Syntax Literate: Jurnal Ilmiah Indonesia p-ISSN: 2541-0849

e-ISSN: 2548-1398

Vol. 5, No. 11, November 2020

\title{
PENERAPAN POMPA AIR FREE ENERGI MENGGUNAKAN KINCIR AIR DAN POMPA HIDROLIK SISTEM UNTUK PENGAIRAN SAWAH
}

\section{Yogi Iskandar dan Aep Saepudin}

Universitas Islam Al-Ihya Kuningan Jawa Barat, Indonesia

Email : yiskandar2@gmail.com dan aepsaepudin050483@gmail.com

\begin{abstract}
In dry season, especially the farmers in Kuningan District Indonesia, face some difficulties in doing agricultural activities. This problem can be solved by a water pump so that agricultural activities can still be carried out, but not all farmers can do activities because only a few people can afford a water pump and fuel, both gasoline and diesel to operate the water pump so it causes financial raising. Solving this problem can be done by making a hydraulic system water pump by utilizing air power from Cijolang River as a source of energy to spin / power / lever the wheel and draw or push air. So that in this way it does not require gasoline / diesel or electric power. By conducted this research, it can assist farmers in solving water supply problems for rice processing. The research method used in this research is an experimental method by making a hydraulic system water pump and measuring $i t$. The results of the research showed that the velocity of air currents in this study is worth 7 seconds / one rotation of the airwheel. The diameter of the water wheel is $1 \mathrm{~m}$ and the water pump diameter is $5 \mathrm{~cm}$ to $10 \mathrm{~cm}$. The need for a water pump for an area of 1000 meters requires 3 to 6 water pumps.
\end{abstract}

Keywords: Agriculture; Water wheel; Hydraulic System Water Pump

\begin{abstract}
Abstrak
Pada musim kemarau petani Indonesia khususnya Daerah Kabupaten Kuningan mengalami kesulitan dalam melakukan aktivitas pertanian. Masalah tersebut dapat di pecahkan dengan adanya pompa air sehingga aktivitas pertanian masih dapat dilakukan, namun tidak semua petani dapat melakukan aktivitas karena hanya sedikit orang yang bisa dan mampu membeli pompa air serta harus membeli bahan bakar baik bensin maupun solar untuk mengoprasikan pompa air tersebut sehingga terjadi pembekakan pembiayaan. Pemecahan masalah tersebut dapat dilakukan dengan cara membuat pompa air sistem hidrolik dengan memanfaatkan tenaga air yang berasal dari arus Sungai Cijolang sebagai sumber energi pemutar/kekuatan/pengungkit kincir dan menarik atau mendorang air. Sehingga dengan cara ini tidak memerlukan bahan bakar bensin/solar ataupun tenaga listrik. Melalui penelitian yang dilakukan oleh peneliti dapat membantu petani dalam memecahkan masalah pengadaan air untuk pengolahan sawah. Metode penelitian yang digunakan dalam penelitian ini adalah metode eksperimen dengan cara membuat pompa air sistem hidrolik selanjutnya dilakukan pengukuran. Hasil pengukurun/ penelitian menunjukan kecepatan arus air dalam penelitian ini senilai 7 detik/ satu kali putaran kincir air.
\end{abstract}


Diameter kincir air sebesar 1 meter dan untuk diameter pompa air $5 \mathrm{~cm}$ s/d $10 \mathrm{~cm}$. Kebutuhan pompa air untuk lahan seluas 1000 meter dibutuhkan 3 s/d 6 pompa air.

Kata Kunci: Pertanian; Kincir Air; Pompa Air Sistem Hidrolik

\section{Pendahuluan}

Dunia teknologi di zaman sekarang terus berkembang pesat sehingga munculnya teknologi terbarukan yang dapat memudahkan manusia dalam melakukan berbagai perkerjaan dalam berbagai industri. Salah satunya industri pertanian, pada industri pertanian begitu banyak alat yan dapat digunakan dalam upaya meningkatkan hasil panen.

Negara Indonesia memiliki potensi yang sangat besar dalam mengembangkan industri pertanian oleh karena itu tidak sedikit orang yang berkonsentrasi untuk terus mengembangkan teknologi pada bidang pertanian. Pertumbuhan hasil pertanian pada produksi padi mencapai dari tahun 2014- 2018 mencapai 2.33\%. (Kementerian Pertanian Indonesia, 2018).

Dengan demikian bahwa sektor pertanian memiliki potensi yang sangat besar. Namun potensi yang dimiliki oleh petani di Indonesia sedikit terhambat hal ini karena indonesia memiliki 2 musim yakni musim kemarau dan musim hujan. Pada musim kemarau petani Indonesia hanya sedikit yang bisa melakukan aktifitas pertanian. Masalah tersebut dapat di pecahkan dengan adanya pompa air sehingga aktifitas pertanian masih dapat dilakukan, namun tidak semua petani dapat melakukan aktifitas karena hanya sedikit orang yang bisa yang mampu membeli pompa air dan harus membeli bensin untuk mengoprasikan pompa air tersebut sehingga terjadi pembekakan pembiayaan.

Untuk pemecahan masalah tersebut dapat dilakukan dengan cara membuat pompa air sistem hidrolik dengan memanfaatkan tenaga air yang berasal dari arus kali cijolang sebagai pemutar/ kekuatan untuk memutarkan kincir dan menarik atau mendorang air. Sehingga tidak memerlukan bahan bakar bensin/solar atau pun tenaga listrik. Terdapat 2 (dua) identifikasi masalah yang ditemukan oleh peneliti pada saat akan melaksanakan penelitian kali ini yang diantaranya adalah (1) Indonesia memiliki 2 (dua) musim kemarau dan musim hujan sehingga pada musim kemarau tidak bisa melakukan aktivitas pertanian. (2) Pompa air yang ada harganya mahal dan memerlukan bahan bakar bensin/solar atau listrik, sehingga tidak semua petani dapat membelinya.

Melalui penelitian yang dilakukan oleh peneliti dapat membantu petani dalam mengatasi pemasalahan pengadaan air untuk pengolahan sawah. Sehingga petani dapat dibantu dan pada akhirnya dapat melakukan aktifitas pertanian serta secara tidak langsung dapat mengurangi beban pembiayaan yang harus dikeluarkan oleh para petani dalam melakukan pengolahan pertanian.

\section{Metode Penelitian}

Metode yang digunakan adalah metode eksperimen dengan cara membuat Pompa Air Free Energy menggunakan kincir air dan pompa sistem hidrolik selanjutnya dilakukan pengukuran penelitian yang sesuai dengan studi rumusan masalah yang telah disusun oleh peneliti.

Desain eksperimen merupakan langkah-langkah dalam melakukan penelitian sehingga dihasilkan data-data yang obyektif sesuai dengan permasalahan, desain eksperimen yang digunakan dalam penelitian ini adalah treatment by subject yaitu 
beberapa variasi perlakuan secara berturut-turut kepada kelompok subyek yang sama. (Aryadi, 2013).

Pengukuran yang akan dilakukan oleh peneliti dimulai dari pengukuran kekuat arus air yang di perlukan untuk memutarkan kincir air, diameter kincir air yang di perlukan untuk mendorong pompa hidrolik dan besarnya diameter pompa hidrolik agar dapat mendorong air dari kali ke sawah serta banyaknya pompa yang dibutuhkan untuk memenuhi kebutuhan air disawah.

$V=S / t$

$V=$ Kecepatan rata-rata

$S=$ Jarak tempuh

$t=$ waktu (donbull, 2012).

Untuk menjaga keselamata kerja pada saat melaksanakan penelitian, peneliti juga memperhatiakan sistem keselamatan. Dimana, kecelakaan kerja adalah kejadian yang tidak terduga dan tidak diharapkan. Tak terdga, oleh karena dibelakang peristiwa itu tidak dapat unsur kesengajaan, lebih-lebih dalam perencanaan (Pertiwi, Tarwaka, Erg, \& Sri Darnoto, 2016).

Langkah dalam menjaga kesehatan dan keselamatan kerja yang dilakukan oleh peneliti dengan menggunakan sistem manajemen pekerjaan yang akan dilakukan. Manajemen pekerjaan disesuaikan, dengan bentuk dan jenis pekerjaan yang akan dilaksanakan dengan caran mengklasifikasikan tahapan-tahapan pekerjaan yang dilakukan.

\section{Hasil dan Pembahasan}

\section{A. Hasil Penelitian}

\section{Kekuat Arus Air yang Diperlukan Untuk memutarkan Kincir Air}

Untuk melakukan kekuatan arus air, peneliti menggunakan rumus kecepatan/ deras arus air. Kecepatan aliran sungai pada satu penampang saluran tidak sama, kecepatan aliran sungai ditentukan oleh bentuk aliran, geometri saluran dan factor-faktor lainnya. Kecepatan aliran sungai diperoleh dari ratarata kecepatan aliran pada tiap bagian penampang sungai tersebut. (Norhadi, Marzuki, Wicaksono, \& Yacob, 2015).

Kecepatan arus air juga dipengaruhi oleh Debit aliran merupakan satuan untuk mendekati nilai-nilai hidrologis proses yang terjadi di lapangan. Kemampuan pengukuran debit aliran sangat diperlukan untuk mengetahui potensi sumberdaya air di suatu wilayah DAS. (Neno, Harijanto, \& Wahid, 2016).

Untuk mengatahui kecepatan arus penelilit melakukan perhitungan sebagai berikut:

$$
\begin{aligned}
V & =S / t \\
S & =200 \mathrm{~cm} \\
t & =7 \text { detik } \\
v & =2 / 7 \\
v & =28 \text { Detik }
\end{aligned}
$$

Dengan jarak dari hulu ke hilir sepanjang $200 \mathrm{~cm}$ serta waktu tempuh 7 detik dihasilkan kecepatan 28 detik. Hal ini menunjukan dengan jarak 200 centi 
meter atau setara dengan 2 meter kecepatan air di kali sungai cijolang cukup kuat. Bentuk pengukuran lain yang dilakukan oleh peneliti ada dengan dengan menghitung start awal kincir air saat berputar sampai ketemu lagi pada titik awal dihasilkan perhitungan sebanyak 7 detik.

Melalui kecepatan yang dihasilkan saat melakukan pengukuran peneliti dapat membuat sebuah simpulan bahwa kekuatan arus air dikali cijolang cukup deras. Sehingga mampu mendorong air dari kali jolang ke sawah yang berada didaerah perbukitan setinggi 7 meter dengan kondi lokasi pertanian cukup tebing. Dengan demikian bahwa melalui kekuatan arus tersebut pompa air hidrolik sistem cukup efektif untuk digunakan oleh petani dalam memenuhi kebutuhan air untuk sawah. Namun hal tersebut juga perlu memperhatikan diameter kincir. Semakin kecil diameter kincir kekautannya juga akan kecil namun jika kincir besar makan kekuatan airnya juga relatif besar.

\section{Diameter Kincir Yang Diperlukan Untuk mendorong Hidrolik}

Kincir air adalah komponen putaran air yang memberikan energi pada poros yang berputar. Kincir air merupakan sarana untuk merubah energi air menjadi energi mekanik berupa torsi pada poros kincir. (Mangihot, 2018). Kincir ari adalah semacam roda besar yang dilengkapi dengan timba atau pengambil air yang terbuat dari bambu yang berputar karena aliran air untuk menaikan air dari sungai kearah sawah yang lebih tinggi posisinya. (Junaidi \& Hendri, 2015). Kincir air adalah jenis turbin air yang paling kuno, sudah sejak lama digunakan oleh masyarakat. (Wahyudi, Cahyadi, \& Purnami, 2012).

Pada umumnya kincir air memang sudah digunakan sejak zaman dahulu. Namun, diameternya begitu besar sedangkan diameter kincir yang akan di teliti oleh peneliti berukuran $100 \mathrm{Cm}$, hal ini karena peneliti selain ingin mencari kekuatan air dalam mendrong pompa. Peneliti ingin mengetahui efektifitas dan efisiensi dalam menggunakan kincir air dan pompa hidrolik sistem untuk pengairan sawah. Pengoprasioan pompa yang mengambil tenaga dari arus air yang disebut sistem mekanikal dimana terjadi putaran pada poros, poros adalah sebuah elemen mesin berbentuk silinder pejal yang berfungsi sebagai tempat "dudukannya" elemen lain. Seperti, puli, spoket, roda gigi, dan kopling dan juga berperan sebagai elemen penerus daya dan putaran dari mesin, (Sonawan \& Hery, 2014). Poros tersebut dimanfaatkan untuk mengoprasikan pompa. Sistem pengoprasian pompa dengan menggunakan poros engkol.

Dengan diameter $100 \mathrm{CM}$ tersebut, petani dapat menyimpan kincir air di rumah ataupun digudang pada saat musim hujan tiba. Sehingga, pada saat musim kemarau petani dapat menggunakan kembali kincir ari tersebut. Melalui metode tersebut petani dapat mengurangi pembiayaan saat melakukan pengolah kebun ataupu sawah yang akan dikelola oleh petani.

Selain dari itu, dengan diameter kincir tersebut dapat cukup kuat dan mampu mendorong air setinggi 7 meter. Apabila lokasi pertanian cukup tinggi maka diameter kinci air dapat diperbesar. Hal tersebut dapat memberikan 
kekutan yang lebih tinggi untuk mendorong air dari kali ke lokasi pertanian. Semankin besar diameter kinci makan air yang akan didorong akan semakin tinggi.

Namun, kekuatan dorongan air dalam memutarkan kincir harus melihat dari kekuatan arus air serta ketinggian sawah atau objek yang akan dialiri air. Jika airnya cukup landay maka air yang akan didorong sedikit lemah. Oleh karena itu, pada saat ingin memanfaatkan pompa air hidrolik ini. Selain diameter kinci kita juga harus memperhatikan arus air yang tersedia di kali.

\section{Diameter Pompa Hidrolik Yang Dapat Mendorong Air Dari Kali Ke Sawah}

Pompa adalah alat atau mesin yang digunakan untuk memindahkan barang-barang ke tempat yang berbeda dari media yang digunakan dengan cara menambahkan energi pada cairan yang berpindah dan terus secara terus menerus. (Bayu Gilang Permono, 2018) Pada konsep penelitian kali ini pompa yang di guanakan adalah pmpa air menggunakan sistem hidrolik.

Pompa air pada umunya mengubah energi mekanik motor menjadi energi aliran fluida. Energi yang diterima oleh fluida akan digunakan untuk menaikkan tekanan dan mengatasi tahanan - tahanan yang terdapat pada saluran yang dilalui. (Mangihot, 2018). Pompa air sistem hidrolik memanfaatkan tekanan dan tarikan melalui sistem mekanikal. Sehingga diperlukan diameter untuk yang sesuai untuk memenuhi kebutuhan para petani.

Terbentuknya tekanan pada pompa air hidrolik dengen menerapkan fungsi piston. Fungsi piston adalah untuk membentuk ruang bakar dan mentrasfer tekanan hasil pembakaran ke pena piston, batang piston (connecting rod) dan poros engkol. Gerak Piston bolak-balik diubah menjadi menjadi putaran pada poros engkol melalui batang piston. (Arif Hidayatullah dan Moch. Solikin, 2011). Penerapa fungsi poston pada motor bakar dapat mengubah arah bolak balin menjadi putaran sedangkan pada pompa air sistem hidrolik mengubah dari putaran menjadi bolak balik yang disebut dengan sistem hirolik.

Sistem hidrolik adalah suatu system pemindah tenaga dengan menggunakan zat cair atau fluida sebagai perantara. Sistem hydraulic ini mempunyai banyak keunggulan dibanding jika menggunakan sistem mekanikal. (Forum IPTEK Pembangunan SMKN 1 Cimahi., 2013).

Diameter pompa yang digunakan pada penelitian ini sebesar $6 \mathrm{~cm}$. Dengan diameter tersebut dapat mendorong air setinggi 7 meter. Untuk mendapatkan hasil yang optimal kita menggunakan dameter sebesar $5 \mathrm{~cm} \mathrm{~s} / \mathrm{d} 10 \mathrm{~cm}$. Ukuran diameter pada pompa air harus disesuaikan juga dengan katup. Katup adalah pralatan yang mengintrol/ megatur baik berjalan, berhenti atau mengarahkan aliran tekanan dari suatu medium tekatan. (Haryanto dan Benny Multi Hidayat, 2000). Penempatan katup pada poma ini mengacu pada (Eka Yogaswara, 2013). Katup jenis I terletak pada satu baru yang digerakan oleh satu poros kam. Jika ukuran katup besar sebaiknya diameter pompa sebesar $10 \mathrm{~cm}$. 
Selain dari diameter kincir dan katup kita harus memperhatikan kerapatan didalam dalam pompa air pompa air yang dibuat harus bener-bener rapat agar pompa dapat berfungsi secara optimum . Pada dasarnya saat kita akan menggunakan sistem ini selain memanfaatkan arus air kita juga memanfaatkan udara yang ada pada pompa air. Udara yang dimanfaatkan inilah yang disebut dengan hidrolik sistem.

Saat pompa beroprasi sebaiknya juga kita membuat penampungan air didalam sistem pompa. Hal ini untuk mencegah air masuk kedalam sistem pendorong dan penarik air didalam pompa air. Jadi saat pompa air sistem hidrolik beroprasi dibantu dengan udara yang ada didalam pompai air. Sehingga, akan membuat air lebih ringan saat ditarik dan didorong oleh pompa tersebut.

Dengan demikian bahwa diameter yang dibutuhkan untuk pengoprasian pompa hidrolik ini adalah $5 \mathrm{~cm} \mathrm{~s} / \mathrm{d} 10 \mathrm{sm}$.

\section{Pompa Yang Dibutuhkan Untuk Memenuhi Kebutuhan Air Untuk Sawah}

Hasil pengukuran penelitian menunjukan bahwa kemampuan pompa air di kali cijolang dengan kecepatan 7 detik serta menghasilkan dorongan terhadap air setinggi 7 meter. Maka semakin tinggi kondisi sawah dari kali akan berpengaruh terhadap kinerja air atau air yang dihasilkan oleh pompa tersebut.

Hal ini tentunya akan berpengaruh pula pada kebutuhan pompa air untuk mengaliri sawah. Sedangkan untuk penelitian yang telah dilakukan saat ini, dapat menghasilkan air atau dapat menyiram sawah seluas $1 \mathrm{~m}^{2}$ dengan kurun waktu selama 5 menit. Jika dalam waktu 5 menit dapat menyiram sawah seluas $1 \mathrm{~m}^{2}$ maka dalam kurun waktu 1 jam akan mengairi sawah seluas $12 \mathrm{~m}^{2}$. Jika sawah tersebut seluas $1000 \mathrm{~m}^{2}$ maka akan membutuhkan waktu $1000 \mathrm{~m}^{2} / 12 \mathrm{~m}^{2}$ $=83$ jam untuk 1 pompa air dengan ketinggian 7 meter dari kali ataupun sungai.

Dari hasil analisis tersebut apabila kita menginginkan waktu yang relatif singkat untuk sawah seluas $100 \mathrm{~m}^{2}$ setidaknya membutuhkan 3 sampai 6 pompa air yang akan beroprasi selama 24 jam.

\section{B. Pembahasan}

Hasil pengukuran menunjukan bahwa kecepatan air dalam satu kali putaran kincir senilai 7 detik. Hal ini menunjukan bahwa arus air kali cijolang cukup kuat. Salah satu indikator dalam penggunaan pompa air dengan menggunakan sistem hidrolik memiliki kekuatan arus yang kuat. Sehingga mampu mentransmisikan tenaga dari kincir ke pompa sehingga mampu memindahkan ari dari kali ke sawah.

Jika dilihat dari diameter kincir air senilai $100 \mathrm{~cm}$, ini menunjukan bahwa penerapan pompa air cukup efisien dibandingkan dengan penggunaan kincir air pada masa sebelumnya. Ukuran kincir air sebelumnya 6 sampai 10 meter, bergantung pada ketinggian sawah yang ada di dekat kali ataupun sungai. Diameter kincir yang digunakan oleh peneliti dapat dijadikan sebagai standar/ batas minimal ukuran dalam memanfaatkan arus sebagai tenaga pengungkit dalam mentransmisikan tenaga dari arus air ke pompa air dengan sistem hidrolik. 
Sedangkan untuk diamater pompa air sebesar $6 \mathrm{~cm}$, hal ini menunjukan bahwa pompa hidrolik dalam penerapan pompa air ini tidak membutuhkan diameter yang begitu besar. Ketika petani ingin menggunakan metode ini dalam pemenuhan kebutuhan air. Diameter minimalnya $6 \mathrm{~cm}$ agar dapat menarik dan mendorong air cukup besar sehingga air yang dihasilkan oleh dalam pengoprasian pompa ini dapat memenuhi kebutuhan air untuk pengolah sawah.

Pengukuran ketinggian air yang dihasilkan adalah 7 meter, hasil pengukuran peneliti memiliki hasil yang senada dengan penelitian yang telah dilakuakn oleh Jamrud Aminuddin, Nurhayati \& Agustina Widiyan (2019). Berdasarkan analisis yang telah dilakukan, dapat diketahui bahwa pompa air menggunakan kincir kecepatan rendah sebagai tenaga penggerak mampu mengangkat air sampai ketinggian 6 meter dengan debit air 0,02 liter per detik.

Dengan demikin penerapan pompa air ini, sudah cukup efektif untuk pesawahan yang memiliki ketinggian antara kali dengan sawah yang senilai 7 meter. Jika ketinggian sawah lebih dari 7 meter kita dapat menambah diameter kincir setidaknya 2 sampai 3 meter agar tenaga yang dihasilkan lebih kuat. Semakin besar diameter kincir kekuatan kincir air akan semakin besar. Namun, dengan memperbesar diameter kincir air yang besar akan berpengaruh pada putaran kinci air. Sehingga diperlukan komponen tambahan agar memiliki putaran yang sama bahkan lebih cepat dibandingkan dengan putaran yang dihasilkan oleh peneliti saat ini.

Kebutuhan pompa air dapat diukur dari luasnya sawah yang dilimiliki oleh petani. Hal ini juga dapat disesuaikan dengan besarnya saluran air dari kali kesawah, jika ingin mempercepat dalam pemenuhan kebutuhan air kita dapat menggunakan salur air yang lebih besar $1 / 2$ atau $1 / 4$ in dapat dijadikan alternatif untuk mempercepat pemenuhan kebutuhan air untuk sawah.

\section{Kesimpulan}

Hasil pengukurun menunjukan kecepatan arus air dalam penelitian ini menghasilkan 7 detik/ satu kali putaran kincir air. Perhitungan ini dimulai start sumbu A sampai kembali pada sumbu A. Sedangkan untuk diameter kincir air kita dapat menggunakan dari mulai 1 meter untuk ketinggian sawah setinggi $7 \mathrm{~m}$. Ketinggian sawah yang lebih dari 7 meter, dapat menggunakan diameter kincir sebesar 5 meter. Untuk diameter pompa air hidrolik dapat menggunakan diameter $6 \mathrm{~cm}$ dengan menggunakan katup buang lebih besar dari pada katup isap. Untuk pemasangan katup, sebaikanya katup buang diameternya lebih besar dibandingkan katup isap. Jika katup isap sebesar $1 / 2$ in maka katup buang $3 / 4$ in. Hal ini dilakukan agar air tidak naik ke bagian piston (pompa hidrolik) sehingga tidak mengganggu pelumas yang akan berdampak pada pemuaian piston sehingga pompa tidak dapat berfungsi secara optimal.

Kebutuhan pompa dalam mengairi sawah dapat ditentukan berdasarkan ketinggian dan luasnya lahan pertanian. Untuk lahan pertanian 1000 meter $^{2}$ dengan ketinggian $7 \mathrm{~m}$ dapat menggunakan kincir berdiameter $1 \mathrm{~m}$ dan diameter pompa $6 \mathrm{~cm}$ serta pompa sebanyak 6 unit. 


\section{BIBLIOGRAFI}

Arif Hidayatullah dan Moch. Solikin, M. Ke. (2011). Service Engine Ringan dan Komponen-Komponen Pada Sepeda Motor. Yogyakarta: Mentari Pustaka.

Aryadi, Widya. (2013). Perbandingan Performa dan Konsumsi Bahan Bakar Motor Diesel Satu Silinder dengan Variasi Tekanan Injeksi Bahan Bakar dan Variasi Campuran Bahan Bakar Solar, Minyak Kelapa dan Minyak Kemiri. Automotive Science and Education Journal, 2(2).

Bayu Gilang Permono. (2018). POMPA HIDRAM. http://www.kelair.bppt.go.id/sitpapdg/Patek/Hidran/hidran.html

donbull. (2012). Cara menghitung Kecepatan. Retrieved from https://rumushitung.com/ 2012/12/14/cara-menghitung-kecepatan/: 10/05/2018

Eka Yogaswara. (2013). Motor Bensin. Bandung: CV.Arfino Raya

Forum IPTEK Pembangunan SMKN 1 Cimahi. (2013). Pompa Air Hidrolik Sistem Tanpa Listrik dan Bensin. http://fortekpembangunan. blogspot.co.id/2013/05/siste m-hidrolilk-dan-pompa-idrolik.html:10/05/ 2018.

Haryanto dan Benny Multi Hidayat. (2000). Teknik Dasar Pneumatik Dasar Hidrolik. Jakarta: CV Al Haman.

Junaidi, A', \& Hendri, A'. (2015). Model fisik kincir air sebagai pembangkit listrik. Riau University.

Jamrud Aminuddin, Nurhayati \& Agustina Widiyani. (2019). Modifikasi Pompa Air Menggunakan Kincir Kecepatan Rendah Sebagai Tenaga Penggerak. Journal of Islamic Science and Technology, 5(1).

Kementerian Pertanian Indonesia. (2018). Retrieved from https://www.pertanian.go.id/Data5tahun/ TPATAP-2017 (pdf)/20-ProdPadi.pdf: 05/08/2019

Mangihot. (2018). http://www.indonesiastudents.com/pengertian-kincir-air-dan-carakerjanyalengkap/:10/05/2018. Retrieved from http://mangihot.blogspot.co.id/201 6/12/pompa.html:10/05/2018 Indonesia students.

Neno, Abdul Kamal, Harijanto, Herman, \& Wahid, Abdul. (2016). Hubungan debit air dan tinggi muka air di sungai lambagu kecamatan tawaeli kota palu. Jurnal Warta Rimba, 4(2).

Norhadi, Ahmad, Marzuki, Akhmad, Wicaksono, Luki, \& Yacob, Rendi Addetya. (2015). studi debit aliran pada sungai antasan kelurahan sungai andai Banjarmasin Utara. Poros Teknik, 7(1). 
Yogi Iskandar dan Aep Saepudin

Pertiwi, Pujiani, Tarwaka, PGDip Sc, Erg, M., \& Sri Darnoto, S. K. M. (2016). Hubungan Antara Perilaku Keselamatan Dan Kesehatan Kerja (K3) Dengan Kejadian Kecelakaan Kerja Pada Pekerja di PT Aneka Adhilogam Karya, Ceper, Klaten. Universitas Muhammadiyah Surakarta.

Sonawan, HERY, \& Hery, Ir. (2014). Perancangan Elemen Mesin. Edisi Revisi. Cetakan Kedua, Maret. Bandung: Alfabeta.

Wahyudi, Slamet, Cahyadi, Dhimas Nur, \& Purnami, Purnami. (2012). Pengaruh Variasi Tebal Sudut Terhadap Kinerja Kincir Air Tipe Sudu Datar. Rekayasa Mesin, 3(2), 337-342. 